\title{
The impact of the Tokyo emissions trading scheme on office buildings: what factor contributed to the emission reduction?
}

\author{
Toshi H. Arimura ${ }^{1,2}$ (D) Tatsuya Abe $e^{1,3}$
}

Received: 31 August 2019 / Accepted: 25 February 2020 / Published online: 18 March 2020

(c) The Author(s) 2020

\begin{abstract}
Tokyo ETS is the first emissions trading scheme to control GHG emissions from office buildings. Although the Tokyo government claimed that Tokyo ETS had been successful, some argued that the emission reduction under Tokyo ETS was actually the result of electricity price increases triggered by the Great East Japan Earthquake in 2011. Using a facility-level data set for Japanese office buildings, we conducted an econometric analysis to examine the impact of Tokyo ETS. We found that half of the emission reduction is a result of the ETS, while the rest of the reduction is due to the electricity price increase. Another unique feature of Tokyo ETS is that an accurate permit price is not publicly available due to its design. Using our estimated model, we found that the price is approximately $\$ 50$ per ton of $\mathrm{CO}_{2}$ in the early phase.
\end{abstract}

Keywords Emissions trading scheme $\cdot$ Electricity $\cdot$ Micro data $\cdot$ Office buildings . Climate change

JEL Classification Q54 - Q41

Toshi H. Arimura

toshi.arimura@gmail.com

Tatsuya Abe

tatsuya.abe149@gmail.com

1 Research Institute for Environmental Economics and Management, Waseda University, Tokyo, Japan

2 Faculty of Political Science and Economics and Research Institute for Environmental Economics and Management (RIEEM), Waseda University, 1-6-1 Nishiwaseda, Shinjuku-ku, Tokyo 169-8050, Japan

3 Graduate School of Economics, Waseda University, Tokyo, Japan 


\section{Introduction}

Carbon pricing has become a popular economic instrument used to help mitigate greenhouse gases (GHGs), which cause climate change. Among carbon pricing techniques, emissions trading schemes (ETSs) have gained attention. Notably, the European Union Emissions Trading Scheme (EU ETS) was the first comprehensive ETS to control carbon dioxide $\left(\mathrm{CO}_{2}\right)$ emissions. In the US, the Regional Greenhouse Gas Initiative (RGGI) started in 2009, followed by the California system. Among Asian countries, Korea was the first country to introduce a cap-and-trade scheme at the national level. Finally, China, the largest emitter of GHG, implemented seven regional ETSs in a pilot scheme and announced that it would introduce a national level ETS starting with the power sector (Duan 2019).

The Japanese government has not yet adopted an ETS at the national level. The Tokyo metropolitan government, however, successfully introduced an ETS, the Tokyo Emissions Trading Scheme (Tokyo ETS), in 2010 (Arimura 2015). This ETS is not only the first cap-and-trade scheme for $\mathrm{CO}_{2}$ emissions in Japan but also the first in Asia. Furthermore, Tokyo ETS is unique among ETSs because the main target of this scheme is office buildings. Indeed, it is the first ETS to regulate GHG emissions from office buildings.

Tokyo ETS consists of several phases. Phase I started in 2010 and ended in 2014. Phase II started in 2015 and implemented a more stringent emission target. At the start of Phase II of Tokyo ETS, the Tokyo metropolitan government reviewed the level of emissions from the regulated buildings and confirmed an emission reduction of $25 \% .^{1}$ It is not clear, however, if the ETS is actually the driver of the emission reduction during this period.

One should note that Japan experienced the Great East Japan Earthquake in 2011, which was followed by the nuclear accident in Fukushima. This nuclear accident affected electricity supply in Japan, but the shortage of electricity capacity was particularly severe in Tokyo because the nuclear power plants in Fukushima belong to the Tokyo Electric Power Company (TEPCO), which is almost a monopoly in supplying electricity to the Tokyo area. Due to the accident, TEPCO had to rely on expensive natural gas to generate electricity, and moreover, it had to compensate for the damages caused by the nuclear accident. This cost was passed to the TEPCO's consumers, and so electricity prices in the Tokyo area increased sharply after the earthquake. Some people, therefore, hypothesized that the reduction in GHG emissions in the Tokyo area was caused by the electricity price increase and not by the ETS. This hypothesis is supported by those who viewed EU ETS with skepticism and thus a doubt whether an ETS could work in the real world is prevalent, especially after seeing the low permit prices in EU ETS.

In addition to the price increase in the electricity, other factors may have contributed to the emission reduction in Tokyo. For example, the Japanese government adopted a rolling blackout immediately after the accident. In this scheme,

1 See Tokyo Metropolitan Government (2016). 
the power companies intentionally stop power supply to one area for a certain period and then shift to stop the power supply to another area while the supply for the first area returns. In this way, the power companies were able to balance the total amount of electricity supply and demand. It could be argued that the experience of the rolling blackout could have incentivized consumers to save energy to avoid future blackouts.

This paper empirically investigates the effects of the Tokyo ETS to clarify the cause of emission reduction in Tokyo using facility-level panel data. By conducting a facility-level survey, we collected data on office buildings in Japan. Our study is not the first to examine Tokyo ETS ex-post. Roppongi et al. (2017) qualitatively reviewed the Tokyo ETS. Wakabayashi and Kimura (2018) conducted a quantitative ex-post analysis of Tokyo ETS with a combination of interviews and facility-level data analysis. However, this latter study suffers from omitted variable bias. Notably, they ignored the influence of the electricity price increase on the GHG emissions from office buildings. This is the first study to examine the impact of Tokyo ETS on emissions by incorporating the impact of the electricity price increase.

This paper contributes to the empirical literature of ETSs. Until recently, researchers have focused on ex-ante analysis using a theoretical analysis or a computable general equilibrium analysis (e.g., Böhringer and Lange 2005). Recently, however, researchers started to conduct ex-post analyses of ETS. For example, Martin et al. (2016) and Ellerman et al. (2016) reviewed the experience of EU ETS. Others initiated ex-post econometric analyses as the ex-post data have become available. For example, Ellerman and Buchner (2008) and Anderson and Di Maria (2011) confirmed the effect of EU ETS on emission reductions in European countries under EU ETS in the first phase. Petrick and Wagner (2014) and Colmer et al. (2018) estimated not only the abatement effect of EU ETS but also its impact on some economic activities using a German and a French facility-level data set. Calel and Dechezlepretre (2016) examined the impact of EU ETS on innovation in European firms, measured with patents. RGGI is also reviewed. Murray and Maniloff (2015) investigated why GHG emissions in RGGI states were reduced and examined the factors contributing to emission reduction in the region. Our study is in line with this stream of literature, but it is unique because we have examined the impact of ETS on office buildings. EU ETS was designed for manufacturing facilities and power plants, and RGGI was designed for power plants, but Tokyo ETS was one of the first ETS focusing on office buildings.

One unique aspect of Tokyo ETS is that the financial sector plays a limited role. The Japanese industry association was against the introduction of ETSs, claiming that ETSs would invite speculation by financial companies. To deal with the criticism, Tokyo government has not established any auction or exchange on the market. Thus, the price of permits in Tokyo ETS is somewhat mysterious. The second contribution of this paper is to reveal the implicit price of the permit through the estimated models.

This paper is constructed as follows. The next section reviews the basic design of Tokyo ETS. Section 3 explains the data, and the estimation results and the discussion are shown in Sect. 4. Finally, Sect. 5 concludes the paper. 


\section{Design of Tokyo ETS}

The Tokyo metropolitan government established an emission target of a $25 \%$ reduction by 2020 from the 2000 level. Initially, they tried a voluntary scheme (Roppongi et al. 2017), but this did not lead to a substantial emission reduction. Thus, the Tokyo government decided to adopt a mandatory emission reduction scheme with flexibility, i.e., an ETS.

Tokyo ETS aims to mitigate the $\mathrm{CO}_{2}$ emissions from large-scale facilities in the commercial and manufacturing sectors. Facilities that consume $1500 \mathrm{kl}$ of crude oil equivalent per year or more are regulated in this system. ${ }^{2}$ The emissions from these facilities amounted to approximately $40 \%$ of total $\mathrm{CO}_{2}$ emissions from the commercial and manufacturing sectors in Tokyo.

The Tokyo ETS was first announced in 2007. The first phase ran from 2010 to 2014 and the second phase is from 2015 to 2019. In the first phase, which is the target of our analysis, the mandatory $\mathrm{CO}_{2}$ reduction targets were $8 \%$ for commercial buildings and $6 \%$ for manufacturing facilities from a base year level. Facilities had the flexibility to choose their baseline emission from the average of 3 consecutive years selected from 2002 to 2007. The emission target was tightened to $17 \%$ for commercial buildings and $15 \%$ for manufacturing facilities in Phase II, which lasted from 2015 to 2019. In 2019, Tokyo metropolitan government announced the details of Phase III, which will continue from 2020 to 2024.

Tokyo ETS is a mandatory scheme, and any facility that cannot attain the goal set by Tokyo ETS faces a fine. This contrasts with Saitama ETS, which was modeled after Tokyo ETS and introduced in 2011. Saitama ETS is a voluntary scheme and thus has no fines (Hamamoto 2020).

A unique feature of Tokyo ETS is that it regulates office buildings as well as industrial plants. Indeed, the number of commercial and office facilities account for approximately $80 \%$ of regulated facilities. In Tokyo, many manufacturing facilities moved to other regions after stringent environmental regulation was enforced in the 1970s and 1980s. Consequently, the majority of GHG emitters in Tokyo belong to the commercial or office sectors. This situation is quite different from that for existing ETSs implemented in other countries at the time of Tokyo ETS adoption in 2010. For example, EU ETS regulated emissions from manufacturing facilities and power plants when it started in 2005. In another case, RGGI is a scheme targeting power plants. The main target of Korean ETS is manufacturing facilities (Jun et al. 2020). Therefore, Tokyo ETS differed from other schemes in 2010 in that it regulated emissions from the service sector.

Though the Tokyo ETS is a regional ETS, there is a high number of regulated facilities. In the Tokyo area, all facilities consuming at least 1500 kiloliters of oil equivalents per year are subject to Tokyo ETS. In 2013, for example, 1392 facilities had to comply with the Tokyo ETS. The number of entities covered by the Korean ETS is approximately 600 (Jun et al. 2020). Thus, there is a high number of entities

\footnotetext{
${ }^{2}$ This is a typical threshold used in energy regulation in Japan. See Arimura and Iwata (2015) for details.
} 
Table 1 Compliance Methods

\begin{tabular}{lll}
\hline & Emission trading & Internal reduction measures \\
\hline Number of facilities & $124(9 \%)$ & $1262(91 \%)$ \\
$\begin{array}{l}\text { Emission reduc- } \\
\text { tions (unit: } 1000\end{array}$ & $193(1.9 \%)$ & $10080(98.1 \%)$ \\
$\left.\mathrm{t}-\mathrm{CO}_{2}\right)$ & & \\
\hline
\end{tabular}

under the Tokyo ETS, although their total emissions are relatively low, at 12 million $\mathrm{CO}_{2}$ tons in 2017, which is less than the emissions covered in the Korean ETS.

Tokyo ETS is also unique in how it measures GHG emissions. The emission from the usage of electricity as indirect emissions, is regulated because the majority of emission from commercial and office buildings are from their electricity usage. This is different from other ETSs, such as EU ETS which focuses on emissions from fossil fuel combustion.

The $\mathrm{CO}_{2}$ emissions from the electricity usage for the facility are measured by multiplying its electricity consumption by the $\mathrm{CO}_{2}$ intensity. The $\mathrm{CO}_{2}$ emission intensity of electricity was $0.382 \mathrm{~kg}-\mathrm{CO}_{2}$ per $\mathrm{kWh}^{3}$ and fixed for the compliance period under Tokyo ETS. According to this method, the total emission under Tokyo ETS was approximately 11.8 million $\mathrm{CO}_{2}$ tons in 2010 .

To mitigate the burden of compliance, the Tokyo ETS provides four types of domestic offset credits. The first is small- and medium-sized installation credits within the Tokyo area. Large regulated facilities can earn credits by investing in energy efficiency in unregulated small and medium size facilities. Second one is outside Tokyo Prefecture credits. Organizations in Tokyo can earn emission reduction credits if they reduce emissions outside of Tokyo. Third, firms can use Saitama credits, i.e., credits from Saitama ETS. Saitama ETS is modeled after Tokyo ETS, and thus, the features of the two systems are similar, and the credits from the two systems are exchangeable. Finally, Tokyo ETS accepts renewable energy certificates. Facilities can earn credits if they invest in renewable energy. International credits such as CDM credits, however, cannot be used to offset GHG emissions in this scheme.

Facilities under Tokyo ETS can achieve their target through several methods. Table 1 shows the compliance methods by entity. First, they can reduce emissions. According to the Tokyo metropolitan government, 91\% of facilities reduced emissions beyond the target. Alternatively, they can achieve their targets by obtaining additional credits. Approximately $9 \%$ of facilities achieved the target through the acquisition of credits.

Permit trading under Tokyo ETS is regulated in a unique manner. When facing the adoption of an ETS, some stakeholders were afraid that permit trading under an ETS could create a "casino (money game)" (Roppongi et al. 2017). The

\footnotetext{
3 This is average $\mathrm{CO}_{2}$ intensity from 2005 to 2007. Under Tokyo ETS, the coefficient is fixed through all periods even when the emission intensity changes as power companies change the fuel mix. This fuel mix is hardly impacted by Tokyo ETS because most of the power plants are located outside Tokyo or Saitama and do not face ETS.
} 
manufacturing sector criticized ETSs by claiming that these systems invite speculation by the financial sector and thus are not effective as an instrument for environmental policy. In response to this criticism, the Tokyo government allows only "reduction credits" and not "emission credits". That is, one can earn credits only after achieving emission reduction. Moreover, there is no auction of permits. Only emitting entities can participate in trading, and the financial sector does not play a crucial role in the system. Consequently, the trades have been bilateral in many cases, and the trading of permits was not very active compared to other markets. The Tokyo government investigates the price through private interviews and publicizes the permit price. The price was initially approximately $10000 \mathrm{JPY}(\$ 125)$ per $\mathrm{CO}_{2}$ ton in 2011, but it fell to approximately $4500 \mathrm{JPY}(\$ 37)$ per $\mathrm{CO}_{2}$ ton in 2015 for reduction credits. These numbers are a reasonable conjecture but may not reflect the "true price" because the Tokyo metropolitan government does not reveal how it constructs prices. ${ }^{4}$

It should be noted that the reduction credits are bankable, and so credits from Phase I can be used in Phase II. However, they can only be carried for one phase; credits from Phase I cannot be used in Phase III.

\section{Data}

We have obtained data from various sources as follows.

\subsection{Facility-level data: mail survey}

We chose the office buildings from among the regulated facilities for several reasons. First, under Tokyo ETS, office buildings represent the largest group among the commercial buildings. Hence, office buildings are the major target of regulations. ${ }^{5}$ Second, among the regulated facilities, office buildings are relatively less influenced by economic fluctuations in terms of energy consumption.

We conducted a mail survey in 2015 . We sent questionnaires to 824 owners of office buildings across Japan. The population of office buildings was chosen from the database, which was constructed based on the Act on the Promotion of Global Warming Countermeasures run by the Ministry of the Environment. Facilities that consume energy more than $1500 \mathrm{kl}$ of crude oil equivalent must report their GHG emissions every year. From this database, we were able to obtain a list of the address of all office buildings. We received 414 replies from the office buildings, representing a reasonably high response rate of $50.2 \%$.

Owners of office building were asked to report their $\mathrm{CO}_{2}$ emissions levels from 2009 to 2013. We also asked for electricity consumption and energy consumption, where energy consumption is the sum of electricity consumption and fossil fuel

\footnotetext{
4 Note that the prices of permits differ if they are "reduction credits" or "renewable credits" because renewable credits can be used for compliance purposes for another regulation in the power sector.

5 There is only one fossil power plant, and there are a small number of manufacturing facilities in Tokyo.
} 


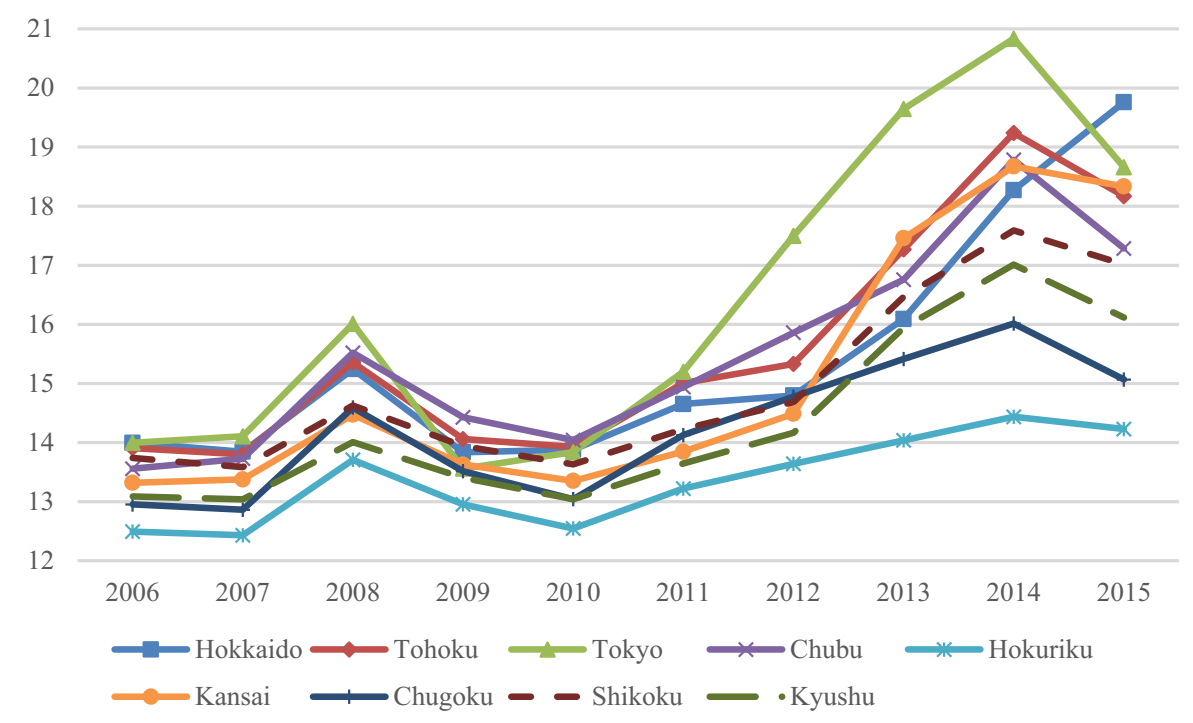

Fig. 1 Changes in electricity prices (JPY/kWh), 2006-2015. Source: the database from the Federation of Electric Power Companies (FEPC) of Japan

consumption. Respondents were also asked to report the number of employees, the floor area, their experience with the rolling blackouts and any other requests for energy savings from the power companies.

\subsection{Electricity price}

We collected data on electricity prices from a publicly available database of the Federation of Electric Power Companies (FEPC) of Japan. Until the recent deregulation of the retail market in 2016, the Japanese power market had been divided into nine regions: Hokkaido, Tohoku, Tokyo, Chubu, Hokuriku, Kansai, Shikoku, Chugoku and Kyusyu. ${ }^{6}$ We obtain charge revenues and volume of power demand for these nine regions from the FEPC. Following Hosoe and Akiyama (2009), we calculated the electricity price for each region by dividing the charge revenue based on the volume of power demand.

The electricity price has increased in Japan over the past 10 years, from 2006 to 2015 (See Fig. 1). Before the Great East Japan Earthquake in 2011, electricity prices for all companies were fairly similar. However, after the earthquake, the price in the jurisdiction of the TEPCO saw a large increase. In particular, industry and commercial sectors in the TEPCO market faced a growth rate for electricity prices of $12.4 \%$ during the period 2010-2013. It was the largest growth rate for electricity prices among the nine regions. For example, during the same period, the second largest

\footnotetext{
${ }^{6}$ Okinawa is excluded from the list because Okinawa is an isolated island.
} 
and the lowest one were recorded in Kansai region and Hokuriku region with each growth rate being $9.4 \%$ and $3.8 \%$, respectively.

TEPCO covers nine prefectures: Tokyo, Saitama, Chiba, Ibaraki, Tochigi, Gunma, Kanagawa, Yamanashi and Shizuoka. Among the nine prefectures, only Tokyo and Saitama have an ETS in place. Therefore, we can disentangle the impact of the ETS from the increase in electricity prices.

\subsection{Savings requests and the rolling blackout}

In addition to electricity prices and ETS, other factors may also influence emissions. The Great East Japan Earthquake in 2011 damaged a few power plants. Most notably, among them is the nuclear power plant in Fukushima. This led to the shutdown of major nuclear power plants. Consequently, TEPCO faced a shortage of power supply. In response to this emergency, TEPCO introduced "rolling blackout". Under this system, TEPCO intentionally stopped the electricity supply to a designated area. After several hours, another area faced the intentional blackout. In this way, TEPCO managed to supply electricity to their customers with limited capacity. In our survey, we asked if they had experienced the rolling blackout.

Another important aspect is demand-side management. In response to the electricity crisis, the government introduced "request to reduce the electricity consumption". In our survey, we asked if the owners received this request.

We suspect that these experiences may have given incentives to save energy for consumers. We construct a dummy variable, saving request/rolling blackout, which takes the value one if the building owners faced either the rolling blackout or the request of electricity consumption reduction. In our sample, $41 \%$ of facilities faced this request.

\subsection{Vacancy ratio of office buildings}

The emissions from office buildings are influenced by economic activities conducted in each building. To capture the economic activities in the building sector, we use the vacancy rate of office buildings in each region as a proxy for the vacancy rates for a building. We exploit publicly available data from Miki Shoji Co., ltd. which provides information on the office market in seven large business regions in Japan: Sapporo, Sendai, Tokyo, Yokohama, Nagoya, Osaka and Fukuoka. Unfortunately, this dataset does not offer information on all prefectures separately. We then assigned values to the office buildings based on proximity.

\subsection{Cooling degree days and heating degree days}

To control the impact of weather conditions, we include cooling degree days (CDD) and heating degree days (HDD). This information is publicly available from the Japan Meteorological Agency. We calculated the CDD and HDD for each prefecture. 
Table 2 Summary statistics for 2009, pretreatment period

\begin{tabular}{|c|c|c|c|c|c|}
\hline & $\mathrm{N}$ & Mean & SD & Min & Max \\
\hline \multicolumn{6}{|l|}{ A. Full sample (mid-98\%) } \\
\hline $\mathrm{CO}_{2}$ emission $\left[\mathrm{t}-\mathrm{CO}_{2}\right]$ & 321 & 7105.4 & 5078.6 & 2410.0 & 36853.0 \\
\hline Electricity consumption [GJ] & 317 & 122545.6 & 87322.9 & 19911.0 & 695922.0 \\
\hline Energy consumption [kl] & 317 & 4086.0 & 2794.0 & 1548.0 & 17954.0 \\
\hline $\mathrm{CO}_{2}$ intensity (electricity) $\left[\mathrm{t}-\mathrm{CO}_{2} / \mathrm{kWh}\right]$ & 313 & 0.000418 & 0.000084 & 0.000258 & 0.000918 \\
\hline Number of employees & 248 & 1950.6 & 2340.6 & 9.0 & 10000.0 \\
\hline Electricity price [JPY/kWh] & 321 & 13.7 & 0.3 & 13.0 & 14.4 \\
\hline \multicolumn{6}{|l|}{ B. Tokyo } \\
\hline $\mathrm{CO}_{2}$ emission $\left[\mathrm{t}-\mathrm{CO}_{2}\right]$ & 124 & 7463.8 & 4869.8 & 2410.0 & 27038.0 \\
\hline Electricity consumption [GJ] & 121 & 133842.4 & 92624.4 & 41294.0 & 695922.0 \\
\hline Energy consumption [kl] & 121 & 4417.6 & 2976.5 & 1548.0 & 17954.0 \\
\hline $\mathrm{CO}_{2}$ Intensity (electricity) $\left[\mathrm{t}-\mathrm{CO}_{2} / \mathrm{kWh}\right]$ & 119 & 0.000438 & 0.000079 & 0.000324 & 0.000759 \\
\hline Number of employees & 97 & 3209.5 & 2723.3 & 23.0 & 10000.0 \\
\hline Electricity price $[\mathrm{JPY} / \mathrm{kWh}]$ & 124 & 13.6 & 0.0 & 13.6 & 13.6 \\
\hline \multicolumn{6}{|l|}{ C. Other regions (excluding Saitama) } \\
\hline $\mathrm{CO}_{2}$ emission $\left[\mathrm{t}-\mathrm{CO}_{2}\right]$ & 179 & 6918.6 & 5278.4 & 2450.0 & 36853.0 \\
\hline Electricity consumption [GJ] & 179 & 115675.3 & 84437.4 & 19911.0 & 454249.0 \\
\hline Energy consumption [kl] & 179 & 3893.6 & 2690.0 & 1550.0 & 15247.0 \\
\hline $\mathrm{CO}_{2}$ Intensity (electricity) $\left[\mathrm{t}-\mathrm{CO}_{2} / \mathrm{kWh}\right]$ & 178 & 0.000431 & 0.00009 & 0.000258 & 0.000918 \\
\hline Number of employees & 138 & 1175.4 & 1658.6 & 9.0 & 9000.0 \\
\hline Electricity price $[\mathrm{JPY} / \mathrm{kWh}]$ & 179 & 13.7 & 0.4 & 13.0 & 14.4 \\
\hline
\end{tabular}

\section{$3.6 \mathrm{CO}_{2}$ intensity}

Following the method required by "Act on Promotion of Global Warming Countermeasures," "7 owners of office buildings calculate their emissions by multiplying their electricity consumption by the $\mathrm{CO}_{2}$ intensity of the power companies from which they purchase electricity. The $\mathrm{CO}_{2}$ intensity, however, varies across power companies and time. After the earthquake in 2011, power companies had to rely heavily on coal power plants. Consequently, their $\mathrm{CO}_{2}$ intensity sharply increased after 2011. Before the earthquake, in 2009 , the $\mathrm{CO}_{2}$ coefficient, on average, was $0.433 \mathrm{~kg}-\mathrm{CO}_{2}$ per $\mathrm{kWh}$, and it rose to $0.524 \mathrm{~kg}-\mathrm{CO}_{2}$ per $\mathrm{kWh}$ in 2013. To control this impact, we include $\mathrm{CO}_{2}$ intensity in the model for $\mathrm{CO}_{2}$ emissions.

\subsection{Summary statistics}

Table 2 illustrates the summary statistics. For some variables, we removed outliers from our analysis. Specifically, we excluded the top and bottom $1 \%$ of the distributions in the sample. The first panel of Table 2 shows summary statistics for

\footnotetext{
7 This act mandates the owner of facilities with the consumption of $1500 \mathrm{kl}$ cued oil equivalent or more to report their $\mathrm{CO}_{2}$ emissions to Japanese Ministry of the Environment annually.
} 
Table 3 Trends of $\mathrm{CO}_{2}$ emissions by region (unit: ton of $\mathrm{CO}_{2}$ )

\begin{tabular}{llll}
\hline & \multicolumn{2}{l}{ Regions } & \\
\cline { 2 - 4 } Year & Tokyo & Saitama & $\begin{array}{l}\text { Other regions (exclud- } \\
\text { ing Tokyo and Saitama) }\end{array}$ \\
\hline 2009 & 8609.4 & 6494.0 & 7448.2 \\
2010 & 8000.8 & 6189.5 & 6990.5 \\
2011 & 6669.3 & 5360.7 & 6707.3 \\
2012 & 7361.1 & 5875.2 & 7761.9 \\
2013 & 7956.4 & 7351.7 & 8380.6 \\
\hline
\end{tabular}

office buildings throughout Japan. On average, the annual $\mathrm{CO}_{2}$ emissions for an office building considering the total sample was 7105 tons of $\mathrm{CO}_{2}$. The summary statistics for office buildings in Tokyo and other regions are shown in the second and third panels of Table 2. From these panels, we find that the annual $\mathrm{CO}_{2}$ emissions from office buildings in Tokyo was 7463 tons of $\mathrm{CO}_{2}$, while office buildings in other regions accounted for 6918 tons of $\mathrm{CO}_{2}$. Hence, office buildings in Tokyo on average emit $\mathrm{CO}_{2}$ more than those in other regions. We also find large differences between buildings in Tokyo and other regions in terms of size. Generally, office buildings in Tokyo have greater floor area and more employees than office buildings in other regions.

Table 3 exhibits the trends of the average annual $\mathrm{CO}_{2}$ emissions from office buildings. The first column shows the emissions in Tokyo. The second column shows emissions in Saitama, which also had an ETS in place. Note that there are only 20 observations in our sample for Saitama. The third column corresponds to emissions from the rest of Japan. One can see that $\mathrm{CO}_{2}$ emissions in Tokyo decreased after the ETS was introduced in 2010, while emissions elsewhere increased in 2013 relative to 2009 .

\section{Econometric model and estimation results}

\subsection{Econometric model}

To quantify the impact of the ETS, we estimated the following equations.

$$
y_{i t}=\tau \cdot \operatorname{TETS}_{i t}+x_{i t}^{\prime} \beta+\mu_{i}+\eta_{t}+\varepsilon_{i t}
$$

In this equation, $y_{i t}$ denotes the dependent variables for building $i$ in year $t$ : we used $\mathrm{CO}_{2}$ emissions, electricity consumption and energy consumption. The variable TETS $_{i t}$ on the right-hand side is a dummy variable that takes a value of one after 2010 if the building $i$ faces the Tokyo ETS, zero otherwise. It allows us to take an approach of difference-in-differences to estimate the causal effect of Tokyo ETS. Thus, our primary interest is the estimate of parameter $\tau$. The vector $x_{i t}$ is composed of some explanatory variables that include the electricity price and a dummy for 
Saitama ETS, which takes a value of one after 2011 if the office building is located in Saitama prefecture. In addition to these variables, the characteristics of facilities and other exogenous factors such as weather or vacancy rate of office buildings that vary over time are included in the vector. Individual fixed effects and year fixed effects are captured by $\mu_{i}$ and $\eta_{t}$. The variable $\varepsilon_{i t}$ is an idiosyncratic error term.

\subsection{Estimation results}

Table 4 exhibits the estimation results from each of three models. Each model has two specifications. Models 1, 3, and 5 are base models, and models 2, 4, and 6 allow two possibilities to be examined: (1) the difference in effectiveness across years and (2) whether the magnitude of the emission reduction depends on the size of the facility. To capture these effects, we added the interaction terms between TETS and the year dummies and the number of employees to the base models. Based on the Hausman's test results, the fixed effect models were accepted in all specifications.

In models 1,3 , and 5 , the estimated $\tau$ 's are negative and statistically significant. These results show the effectiveness of Tokyo ETS. The size of the coefficient in model 1 is 0.067 , suggesting that Tokyo ETS contributed to a $6.9 \%^{8}$ average annual reduction in GHG emissions.

In addition, the interaction terms for the year dummies and Tokyo ETS are included in models 2, 4 and 6 . The coefficients of these terms indicate whether the Tokyo ETS had different effects on energy usage between 2011 and 2013. We find that the coefficients of the interaction terms of the year and Tokyo ETS are negative and statistically significant. More specifically, the estimation results show that the Tokyo ETS had a relatively large impact on energy usage in 2011 and 2013 compared to its average impact from 2010 to 2013. To see if the three coefficients of the interaction terms are the same or not, we conducted the $F$ test under the null hypotheses for linear restrictions. The results show that there are no statistically significant differences. Thus, our preferred model specification is model 1.

We also find that the Saitama ETS dummy is negative and statistically significant in many specifications except for models 1 and 5. This result suggests that Saitama ETS was useful in reducing GHG even though it is voluntary. We did not estimate the model interacting the year dummy and Saitama ETS because of the limited number of office buildings in Saitama.

Furthermore, the results from models 2, 4 and 6 show that the coefficients of the interaction terms of the building size (employee) and Tokyo ETS are negative and statistically significant. This result suggests that the larger the building is, the greater the emission reduction is. This is an intuitive result because one would expect more room for reduction for larger facilities.

The coefficients of electricity price are negative and statistically significant. In particular, the estimates in the electricity consumption models imply that the price elasticity of demand for electricity consumption is $0.42-0.45 \%$. For the purpose of

\footnotetext{
${ }^{8}$ It is calculated by the formula $\exp (\bullet)-1$.
} 


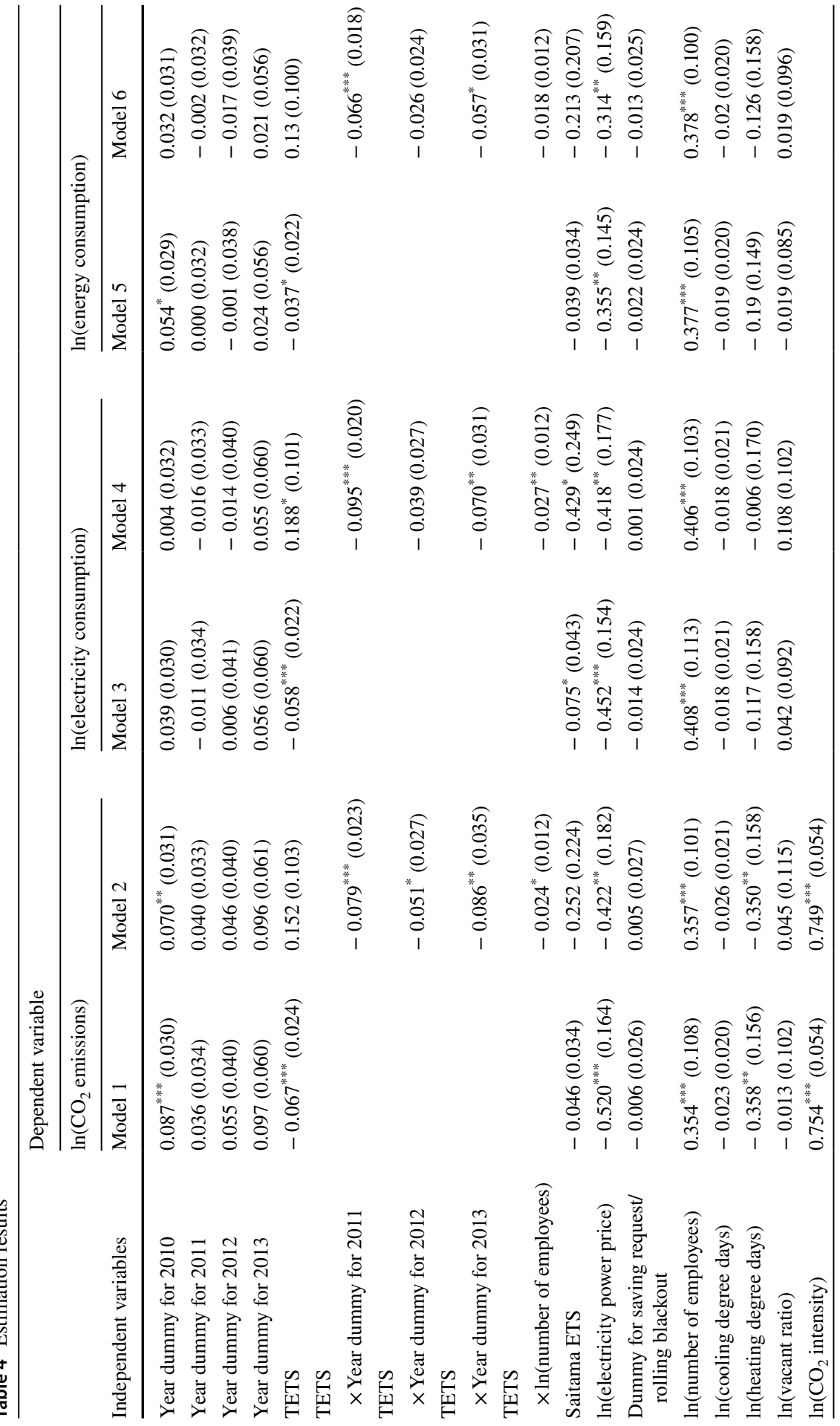




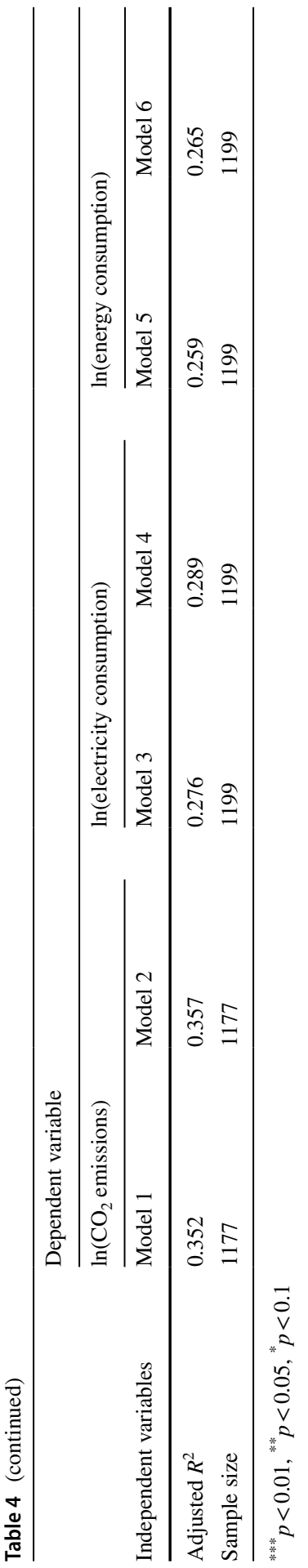


Table 5 Emission reduction decomposition and implicit permit price

\begin{tabular}{ll}
\hline Impact of Tokyo ETS on $\mathrm{CO}_{2}$ emission reductions & $6.9 \%$ \\
\hline $\begin{array}{ll}\text { Rate of electricity price increase that ensures the } \\
\mathrm{CO}_{2} \text { emission reductions of } 6.9 \%\end{array}$ & $13.3 \%$ \\
Implicit permit price of Tokyo ETS & $4688 \mathrm{JPY}(\$ 52)$ \\
\hline
\end{tabular}

comparison with existing literature, note that our estimates are for commercial sector. Hosoe and Akiyama (2009) estimated the price elasticity of electricity demand in industrial and commercial sectors in Japan, suggesting that it ranges from 0.09 to 0.30 in the short run. Although our estimates of the elasticity seem to be relatively higher, they are comparable when we consider the confidence interval of the estimate.

Looking at the coefficients of the dummy variable for the saving request/rolling blackout, which capture the existence of a request for voluntary power savings or experience of the rolling blackout, we find no impacts on $\mathrm{CO}_{2}$ emissions, electricity consumption of energy consumption.

\section{Discussion}

As shown in the previous section, our preferred specification is model 1, and thus we discuss the results using model 1. First, we can compare the impact of the ETS with that of the electricity price increase. Our estimation results suggest that the Tokyo ETS reduced $\mathrm{CO}_{2}$ emissions by $6.9 \%$ annually. At the same time, the electricity price in TEPCO increased by $12.4 \%$ from 2010 to 2013 . Because the price elasticity in the model 1 was estimated at $0.52 \%$, our estimation results imply that the emission reduction due to the electricity price increase is approximately $6.4 \%$. Thus, the impact of the ETS is comparable to the impact of the electricity price increase. Despite the skepticism regarding ETSs, the ETS indeed had a positive impact on emission reduction. We illustrated the results in Table 5.

Second, we can also estimate the implicit permit price of Tokyo ETS from our estimation results. ${ }^{9}$ The estimates are shown in Table 5 . We obtained the fact that the Tokyo ETS caused $\mathrm{CO}_{2}$ emissions to reduce by $6.9 \%$. One can calculate how this translates to the price increase for the electricity. Given the estimated price elasticity in the model 1, i.e., 0.52, the impact of the Tokyo ETS on $\mathrm{CO}_{2}$ emission reductions corresponds to the impact of a $13.3 \%(=0.069 / 0.52)$ increase in electricity price. The electricity price under the TEPCO jurisdiction was 13.8 JPY per kWh in 2010. If the price of power increased by $13.3 \%$, the electricity price of $13.8 \mathrm{JPY}$ per $\mathrm{kWh}$ would have been 15.6 JPY per kWh, which is an increase in the electricity price by $1.8 \mathrm{JPY}$ per $\mathrm{kWh}$. The $\mathrm{CO}_{2}$ intensity for TEPCO was 0.000384 ton of $\mathrm{CO}_{2}$ per $\mathrm{kWh}$ in 2010. Thus, the implicit carbon price is estimated to be $4,688(=1.8 / 0.000384)$

\footnotetext{
9 The technical derivation of the procedure is shown in appendix.
} 


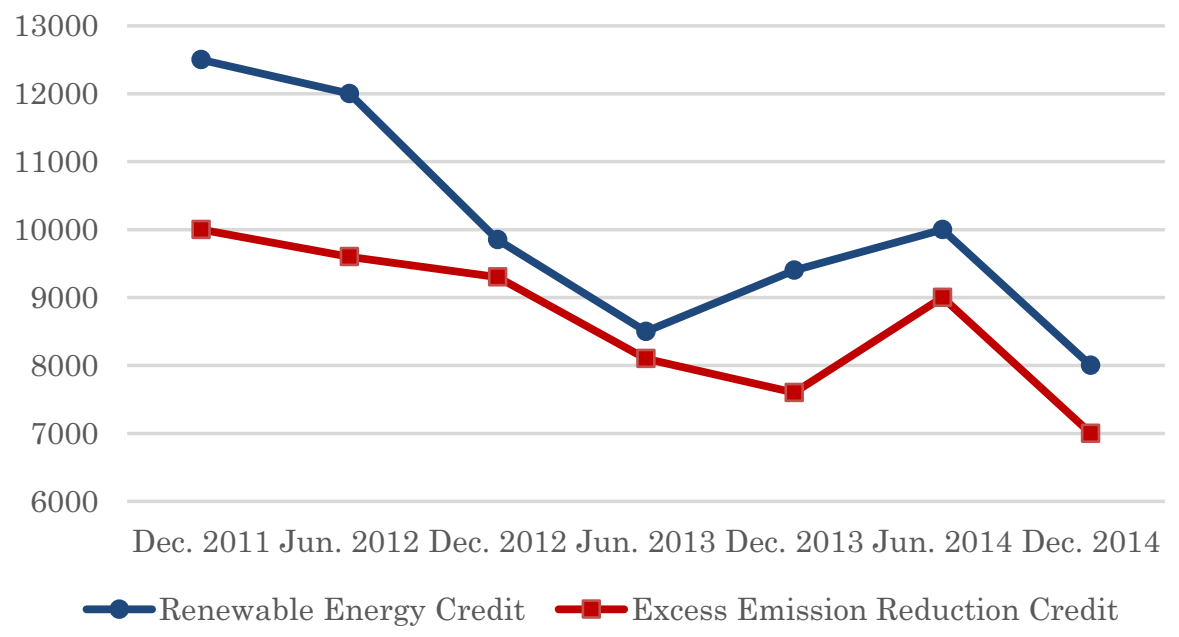

Fig. 2 Permit price (JPY/ $\mathrm{CO}_{2}$ ton): Tokyo ETS

JPY per ton of $\mathrm{CO}_{2}$ (approximately $\$ 52^{10}$ per ton of $\mathrm{CO}_{2}$ ), which is comparable to the permit price reported by the Tokyo government depicted in Fig. 2. The price in 2011 was more than \$125 and fell to \$66 in 2014.

Finally, we discuss the size of the emission reduction. Our estimation results show that the ETS reduced emissions in Tokyo by $6.9 \%$ and that the electricity price increase contributed another $6.4 \%$ reduction. In sum, emissions in Tokyo were reduced by $13.3 \%$. This number seems rather small compared to the reduction of $25 \%$ reported by the Tokyo government. This gap can be explained by two reasons. First, the Tokyo government uses the baseline emission while we use 2009 as our reference for the emissions reduction. The baseline for each facility was chosen from the average of three consecutive years from 2002 to 2007. Therefore, facilities tended to choose years for which they had higher emissions. This difference explains a major part of the gap. Second, Tokyo ETS was announced in 2007. Therefore, some facility managers may have started the reduction in 2008 or 2009. Consequently, the estimated reduction from our estimation would again be smaller than the number from the Tokyo government. Wakabayashi and Kimura (2018) also report an emission reduction under Tokyo ETS of $14 \%$ as of 2014, the last year of the first phase, compared with the 2009 level, which is close to our estimate of $13.3 \%$.

\section{Conclusion}

In this paper, we empirically investigated the impacts of Tokyo ETS using individual facility-level data of office buildings. We found that the Tokyo ETS overall has been successful in reducing $\mathrm{CO}_{2}$ emissions relative to other regions. As expected, the electricity price increase contributed to emission reduction in Tokyo, the ETS

$\overline{10}$ According to the exchange market, one US dollar was valued at approximately 90 JPY in 2011. 
also contributed to it. Thus, despite skepticism regarding the effectiveness of ETSs, it was proven that Tokyo ETS is an effective environmental policy tool.

We also recovered the implicit carbon permit price using our estimated model, which we found to be approximately $\$ 50$ per $\mathrm{CO}_{2}$ ton. This price is somewhat lower than that in the Tokyo government report but still in a comparable range. One can note that the permit price in Tokyo is higher than the carbon price in Europe or North America (World Bank Group 2019). Most of the permit prices in China's pilot scheme have been less than $\$ 15$ (Duan 2019), and the permit price in the Korean market has been stable at less than $\$ 20$ (Jun et al. 2020). Thus, Tokyo ETS seems to have a higher carbon price.

Other aspects of Tokyo ETS, however, should be scrutinized in future work. For example, Tokyo ETS may have caused carbon leakage to other regions in Japan. Because neighborhood prefectures such as Kanagawa or Chiba have not introduced an ETS, some business may have moved or shifted economic activities to these areas from Tokyo. This is an important area of future work.

Acknowledgments This research was supported by the Environment Research and Technology Development Fund (2-1707) of the Environmental Restoration and Conservation Agency. We also appreciate the financial support from the Research Institute for Environmental Economics and Management (RIEEM), Waseda University. We appreciate comments from Richard Morgenstern and participants at the workshop at RFF. Toshi Arimura also appreciates the financial support from JST CREST Grant Number JPMJCR15K2.

Open Access This article is licensed under a Creative Commons Attribution 4.0 International License, which permits use, sharing, adaptation, distribution and reproduction in any medium or format, as long as you give appropriate credit to the original author(s) and the source, provide a link to the Creative Commons licence, and indicate if changes were made. The images or other third party material in this article are included in the article's Creative Commons licence, unless indicated otherwise in a credit line to the material. If material is not included in the article's Creative Commons licence and your intended use is not permitted by statutory regulation or exceeds the permitted use, you will need to obtain permission directly from the copyright holder. To view a copy of this licence, visit http://creativecommons.org/licen ses/by/4.0/.

\section{Appendix: derivation of implicit permit price}

We can derive the implicit permit price as follows. We will consider how much the price of electricity should increase to have the same impact of ETS. Let $\Delta P^{\text {electricity }}$ be the price increase of the electricity necessary to have the same impact of Tokyo ETS. Then, it should hold

$$
(\text { Emission Reduction due to ETS })=\Delta P^{\text {electricity }} \times \varepsilon^{\text {electricity }},
$$

where $\varepsilon^{\text {electricity }}$ denotes the electricity price elasticity of $\mathrm{CO}_{2}$ emission estimated in model 1. Now let $\mathrm{CO}_{2}$ Intensity denote the $\mathrm{CO}_{2}$ intensity of the electricity power generation (ton of $\mathrm{CO}_{2}$ per $\mathrm{kWh}$ ) in a power company and $P^{\text {implicit }}$ be the implicit permit price. Then, it should hold 


$$
\Delta P^{\text {electricity }}=\mathrm{CO}_{2} \text { Intensity } \times P^{\text {implicit }} .
$$

From Eqs. (A.1) and (A.2), one can compute the implicit price of emission trading permits.

\section{References}

Anderson B, Di Maria C (2011) Abatement and allocation in the pilot phase of the EU ETS. Environ Resour Econ 48(1):83-103

Arimura TH (2015) Japanese Environmental Policy in the Routledge Handbook of Environmental Economics in Asia. Edited by Shunsuke Managi, pp 516-531

Arimura TH, Iwata K (2015) The evaluation of "Comprehensive Management Under the Act on the Rational Use of Energy" as a measure to combat climate change for the hotel industry. In: An evaluation of Japanese environmental regulations. Springer, Dordrecht, pp 123-143. https://doi. org/10.1007/978-94-017-9947-8_6

Böhringer C, Lange A (2005) Economic implications of alternative allocation schemes for emission allowances. Scand J Econ 107(3):563-581

Calel R, Dechezlepretre A (2016) Environmental policy and directed technological change: evidence from the European carbon market. Rev Econ Stat 98(1):173-191

Colmer J, Martin R, Muûls M, Wagner UJ (2018) Emission trading, firm behavior, and the environment: evidence from french manufacturing firms. In: Presented at NBER Summer Institute 2018 environmental \& energy economics, Cambridge, MA, USA

Duan M (2019) Performance of the pilot carbon emissions trading systems in China. In: Presented at the Anuutal Meeting of the Eastern Asians Associaion of Environment and Resource Economics, Beijing, China.

Ellerman AD, Buchner BK (2008) Over-allocation or abatement? A preliminary analysis of the EU ETS based on the 2005-06 emissions data. Environ Resour Econ 41(2):267-287

Ellerman AD, Marcantoniniy C, Zaklan A (2016) The European Union emissions trading system: ten years and counting. Rev Environ Econ Policy 10(1):89-107

Hamamoto M (2020) Impact of the Saitama Prefecture target-setting emissions trading program on the adoption of low-carbon technology. Environ Econ Policy Stud (Forthcoming)

Hosoe N, Akiyama SI (2009) Regional electric power demand elasticities of Japan's industrial and commercial sectors. Energy Policy 37(11):4313-4319

Jun S-H, Kim JY, Oh H (2020) Evaluating mitigation performance of phase 1 of the KETS. Mimeo

Martin R, Muûls M, Wagner UJ (2016) The Impact of the European Union emissions trading scheme on regulated firms: what is the evidence after ten years? Rev Environ Econ Policy 10(1):129-148

Murray BC, Maniloff PT (2015) why have greenhouse emissions in RGGI States declined? An econometric attribution to economic, energy market, and policy factors. Energy Econ 51:581-589

Petrick S, Wagner UJ (2014) The impact of carbon trading on industry: evidence from German Manufacturing Firms. Kiel Working Paper 1912

Roppongi H, Suwa A, Jose A, De Oliveira P (2017) Innovating in sub-national climate policy: the mandatory emissions reduction scheme in Tokyo. Clim Policy 17(4):516-532

Tokyo Metropolitan Government (2016) Tokyo cap-and-trade program achieves $25 \%$ reduction after 5 th year. http://www.kankyo.metro.tokyo.jp/en/climate/cap_and_trade/index.files/3c08a5ad895b513 0cb1d17ff5a1c9fa4.pdf. Accessed 18 Aug 2019

Wakabayashi M, Kimura O (2018) The impact of the Tokyo Metropolitan Emissions Trading Scheme on reducing greenhouse gas emissions: findings from a facility-based study. Climate Policy 18(8):1028-1043

World Bank Group (2019) State and trends of carbon pricing 2019. World Bank, Washington, DC

Publisher's Note Springer Nature remains neutral with regard to jurisdictional claims in published maps and institutional affiliations. 